\title{
Ten years of follow-up data in psoriatic arthritis: results based on standardized monitoring of patients in an ordinary outpatient clinic in southern Norway
}

Glenn Haugeberg ${ }^{1,2^{*}}$, Brigitte Michelsen ${ }^{1}$, Stig Tengesdal ${ }^{1}$, Inger Johanne Widding Hansen ${ }^{1}$, Andreas Diamantopoulos ${ }^{3}$ and Arthur Kavanaugh ${ }^{4}$

\begin{abstract}
Background: Over the last decade, a treat-to-target (T2T) strategy has been recommended for psoriatic arthritis (PsA) and new treatment options have become available. There is a lack of data on PsA regarding any changes that may have occurred over these past years. Thus, the main aim of this study was to look for changes in clinical disease status and treatment in a PSA outpatient clinic population monitored over the period 2008 to 2017.

Methods: Annual data collection included demographic data, laboratory (erythrocyte sedimentation rate (ESR) and C-reactive protein (CRP)) and clinic measures of disease activity (e.g., 28 and 32 joint count Disease Activity Score (DAS28), Clinical Disease Activity Index (CDAl), and modified Disease Activity index for Psoriatic arthritis (DAPSA)), evaluator's global assessment, and patient-reported outcomes (PROs), including for example measures of physical function, pain, and patient global assessment. Disease-modifying antirheumatic drug (DMARD) use was also registered.
\end{abstract}

Results: In the PsA outpatient clinic population over the 10-year period (annual mean number of patients, 331) the mean (standard deviation) age was 58.4 (12.4) years, disease duration was 9.6 (7.9) years, 49.4\% were female, and 17.6\% were current smokers. From 2008 to 2017, no statistically significant increase in remission rates was seen for DAPSA $(13.5 \%$ and $22.0 \%)$ or Boolean remission (6.6\% and $8.9 \%)$, whereas a statistically significant increase was seen for DAS28-ESR (36.8\% and 50.6\%) and CDAI (20.0\% and 29.6\%), but not for the last 5 years (DAS28-ESR, $42.3 \%$ and 50.6\%; CDAl, 27.9\% and 29.6\%). Furthermore, over the 10-year period no significant improvement for PROs and no significant change in the use of synthetic (annual mean 53.0\%) and biologic DMARDs (annual mean 29.9\%) was found.

Conclusion: Our data suggest that even in the biologic treatment era there is an unmet need for treating PsA patients to target remission. New treatment options and the development of more feasible and valid outcome measures for use in a T2T strategy in ordinary clinical practice may in the future to further improve clinical outcomes in PSA.

Keywords: Psoriatic arthritis, Clinical outcome, Disease activity, Patient-reported outcome measures, Treat to target, Real life registries

\footnotetext{
* Correspondence: glenn.haugeberg@sshf.no

${ }^{1}$ Division of Rheumatology, Department of Medicine, Hospital of Southern

Norway Trust, Servicebox 416, 4604 Kristiansand, Norway

${ }^{2}$ Department of Neuroscience, Division of Rheumatology, Norwegian

University of Science and Technology, Trondheim, Norway

Full list of author information is available at the end of the article
}

(c) The Author(s). 2018 Open Access This article is distributed under the terms of the Creative Commons Attribution 4.0 International License (http://creativecommons.org/licenses/by/4.0/), which permits unrestricted use, distribution, and reproduction in any medium, provided you give appropriate credit to the original author(s) and the source, provide a link to the Creative Commons license, and indicate if changes were made. The Creative Commons Public Domain Dedication waiver (http://creativecommons.org/publicdomain/zero/1.0/) applies to the data made available in this article, unless otherwise stated. 


\section{Background}

In the new millennium, new treatment strategies (early intervention and treat-to-target (T2T)) have become the new standard of clinical follow-up for patients with chronic inflammatory joint disorders [1]. The T2T strategy was first recommended for use in rheumatoid arthritis (RA) where its significant impact on improved clinical outcome has been convincingly documented [2, 3]. Encouraged by the evidence in RA, an international task force in 2012 recommended the T2T strategy also be used in spondyloarthritis $(\mathrm{SpA})$, including psoriatic arthritis (PsA). The recommendations, however, were mainly based on expert opinion [4]. With new data available strengthening these recommendations, a revised updated version was published in 2018 [5].

In the new millennium, new treatment options with a broad range of targeted modes of action have become available for treatment of chronic inflammatory joint disorders, including PsA [6].

Most data available in the literature are based on selected patient groups included in, for example, registries or clinical studies. Data reflecting unselected outpatient clinic cohorts with data obtained from patients monitored using clinical outcome measures are rare.

We have previously published data on 10-year change in disease status and treatment for RA based on standardized monitoring in an ordinary outpatient clinic in southern Norway [7]. In that study, we documented the dramatic improvement in clinical outcomes and prognosis for RA that took place in a Norwegian outpatient clinic in the period from 2004 to 2013 [7]. To our knowledge, no longitudinal observational study data exist on changes in clinical outcomes and treatment for PsA outpatients reflecting an entire PsA outpatient clinic cohort monitored with standardized outcome measures as part of ordinary clinical practice.

Thus, the aim of this study was to explore the long-term changes in clinical disease status and treatment in Norwegian PsA outpatients, monitored as part of standard clinical care in the era of biologic treatment.

\section{Methods}

\section{Patients and data collection}

The outpatient rheumatology clinic serves a population of approximately 290,000 inhabitants living in the two most southern counties in Norway. In the same geographic era there are also two private practicing rheumatologists.

At the outpatient clinic, the standard for monitoring patients with recommended outcome measures was first introduced in 2003 for RA patients. In 2005, the computer software program GoTreatIT ${ }^{\circledR}$ Rheuma (www.diagraphit.com) was implemented at the outpatient clinic, facilitating patient monitoring with selected outcome measures. During 2007, regularly monitoring of not only
RA but also PsA patients was implemented as part of standard clinical care. For RA patients, no specific protocol for tight control or any specific treatment protocol was used [7]. Treatment and follow-up visits were based on the treating doctor's judgment performed in accordance with national recommendations and, after 2007, also in accordance with the Norwegian tender system for prescription of biologic disease-modifying antirheumatic drugs (bDMARDs).

The same standard outcome measures used for monitoring RA patients at the outpatient clinic were also applied to monitor the PsA patients. Patient-reported outcome (PRO) measures included the Modified Health Assessment Questionnaire (MHAQ) assessing physical function [8], visual analog scales (VAS; 0-100 mm) used to report pain, joint pain, fatigue, and patient global assessment (PGA). Morning stiffness was reported in 15-min units. Standard assessment did not include assessment of skin, nails, entheses, or dactylitis.

Standardized 28 and 32 swollen and tender joint counts were performed by rheumatologists or by trained nurses. The 32-joint count included the 28-joint count plus standardized joint count of ankles and metatarsophalangeal joints (MTP) joints, both scored from 0-2 (the MTP joints were scored as one joint). Laboratory markers of inflammation included C-reactive protein (CRP; $\mathrm{mg} / \mathrm{L})$ and erythrocyte sedimentation rate (ESR; $\mathrm{mm} / \mathrm{h})$. The 28-joint composite Disease Activity Score (DAS) with ESR (DAS28-ESR) [9], the Clinical Disease Activity Index (CDAI) [10], and a modified version of the Disease Activity index for Psoriatic arthritis (DAPSA) including a 32-joint count instead of the original 66/68-joint count was calculated [11]. The evaluator's (trained nurse or rheumatologist) global assessment (EGA) of disease activity was reported on a VAS $(0-100 \mathrm{~mm})$. Data on rheumatoid factor (RF) were also recorded.

We used the cut-offs for DAS28-ESR, CDAI, and DAPSA to define remission, low disease activity, moderate disease activity, and high disease activity $[10,12,13]$. We also applied the suggested DAS28-ESR cut-off from Salaffi et al. of 2.4 instead of 2.6 for defining remission in PsA [14]. Furthermore, the Boolean remission criteria in accordance with the new American College of Rheumatology/European League Against Rheumatism (ACR/EULAR) guidelines for remission were tested [15].

Previous and current treatment use was systematically registered and updated at all visits, including use of prednisolone, synthetic DMARDs (sDMARDs), and bDMARDs. Demographic data collected included gender, age, weight, height, body mass index (BMI), smoking status, disease duration, and work status. From 2010 onwards, self-reported height and weight, smoking status, years of education, and work status were included 
as part of the standard routine with the use of the computer program. In the analysis we only included PsA patients who fulfilled the Classification for Psoriatic Arthritis criteria (CASPAR) and who were 18 years or older [16]. Data retrieved from the computer were based on data from the last annual patient visit for each year.

\section{Statistical analysis}

Continuous variables are presented as mean and standard deviation (SD). Categorical variables are presented as numbers and percentages. To look for a change in variables and associations over the 10-year period and the last 5 years of this period we used linear regression for continuous variables and the Chi-square test for categorical variables. A $p$ value of $<0.05$ was taken to be statistically significant.

\section{Results}

The number of PsA patients with at least one annual visit during the follow-up period ranged from 106 patients in 2008 to a maximum of 412 in 2014, with a mean annual number of 331 patients. From 2008 to 2010, the number of PsA patients increased from 106 to 318 and thereafter stabilized at a mean annual number of 367 patients in the subsequent years.

Data for gender, age, BMI, years of education, full time job status, smoking status, disease duration, and RF status are shown in Table 1. Apart from age and disease duration, no statistically significant differences during follow-up were seen, as shown in Table 1. Over the 10 -year period, mean annual proportions were: females 49.4\%; patients with a full-time job (age $<65$ years) 35.8\%; current smokers 17.6\%; and RF-positive patients $4.8 \%$. Mean (SD) annual values for the period were: age, 58.4 (12.4) years; BMI 27.6 (4.7) kg/m²; education 12.5 (3.6) years; and disease duration 9.6 (7.9) years.

Table 2 shows the measures of disease activity displayed for each year in the 10-year period. A statistically significant improvement in all disease activity measures was seen for the 10-year period; however, for the last 5 years of follow-up (2013-2017) a statistically significant improvement was only seen for ESR and for DAS28-ESR, but not for CRP, joint count, CDAI, modified DAPSA, or EGA.

Comparing the two joint counts, the swollen/tender 32 -joint count was a mean of $0.1 / 0.3$ higher than the 28-joint count (annual detailed data for 32-joint counts are not shown).

As shown in Fig. 1, the proportion of patients in remission was dependent on the composite measures used. The lowest remission rates were found when applying the ACR/EULAR Boolean criteria (range 3.6\% to 9.5\%) and the modified DAPSA criteria (range 12.2\% to 23.0\%). The highest remission rates were shown for the
DAS28-ESR criteria (range $42.1 \%$ to $63.1 \%$ ) and CDAI criteria (range $13.5 \%$ to $30.2 \%$ ), both developed and validated for use in RA. When using the DAS28-ESR cut off $\leq 2.4$, as recommended by Salaffi et al. to be applied when used in PsA [14], the remission rates were lower (range $32.4 \%$ to $50.6 \%$ ); however, these were still significantly higher than for DAPSA and the ACR/EULAR Boolean remission criteria. A significant increase over the 10-year period was only seen for DAS28-ESR and CDAI remission and not for Boolean and DAPSA remission. For the last 5 years of follow-up, no significant change in remission rates occurred for any of the remission criteria.

As shown in Table 3, no significant improvement was seen for either the 10-year period or the last 5 years of follow-up for PRO measures. In contrast, in the last 5 years of follow-up, a small but statistically significant deterioration was seen for MHAQ, pain, joint pain, and morning stiffness, but not for fatigue or PGA.

In Table 4 the proportions of PsA patients treated with prednisolone, sDMARD, and bDMARD monotherapy or combination therapy are shown. The proportion of patients on no treatment declined significantly over the 10 -year period from approximately $30 \%$ in 2008 to approximately $20 \%$ in 2017 . The proportion of PsA patients using prednisolone (annual mean 14.9\%, range $12.6 \%$ to $22.6 \%$ ), sDMARDs (annual mean $53.0 \%$, range $50.7 \%$ to $56.3 \%$ ), and bDMARDs (annual mean 29.9\%, range $23.5 \%$ to $32.8 \%$ ) remained stable overall over the 10 -year period. The use of sDMARDs was dominated by the use of methotrexate, and bDMARDs by the use of tumor necrosis factor (TNF) inhibitors. The annual mean percentage of PsA patients using the different sDMARDs was $38.5 \%$ for methotrexate, $11.2 \%$ for leflunomide, $2.4 \%$ for sulfasalazine, and $0.9 \%$ for other sDMARDs. Only a few PsA patients were treated with bDMARDs with modes of action other than TNF inhibitors: ustekinumab and sekukinumab. However, the use of sekukinumab, which was introduced in Norway in 2016, for PsA-treated patients increased from $0.6 \%$ in 2016 to $2.6 \%$ in 2017.

The use of a combination of sDMARDs and bDMARDs was also stable over the years (annual mean 15.9\%, range $13.4 \%$ to $18.9 \%$ ). Detailed information on use of specific sDMARDs and bDMARDs is shown in Table 4.

Over the 10-year period, significantly more PsA patients had been ever-users of bDMARDs, ranging from $27.6 \%$ in 2009 to $46.0 \%$ in 2017; however, for the last 5 years no significant increase for ever-use of bDMARDs was found.

\section{Discussion}

In our PsA outpatient clinic population for the 2008 to 2017 period, a statistically significant improvement in 


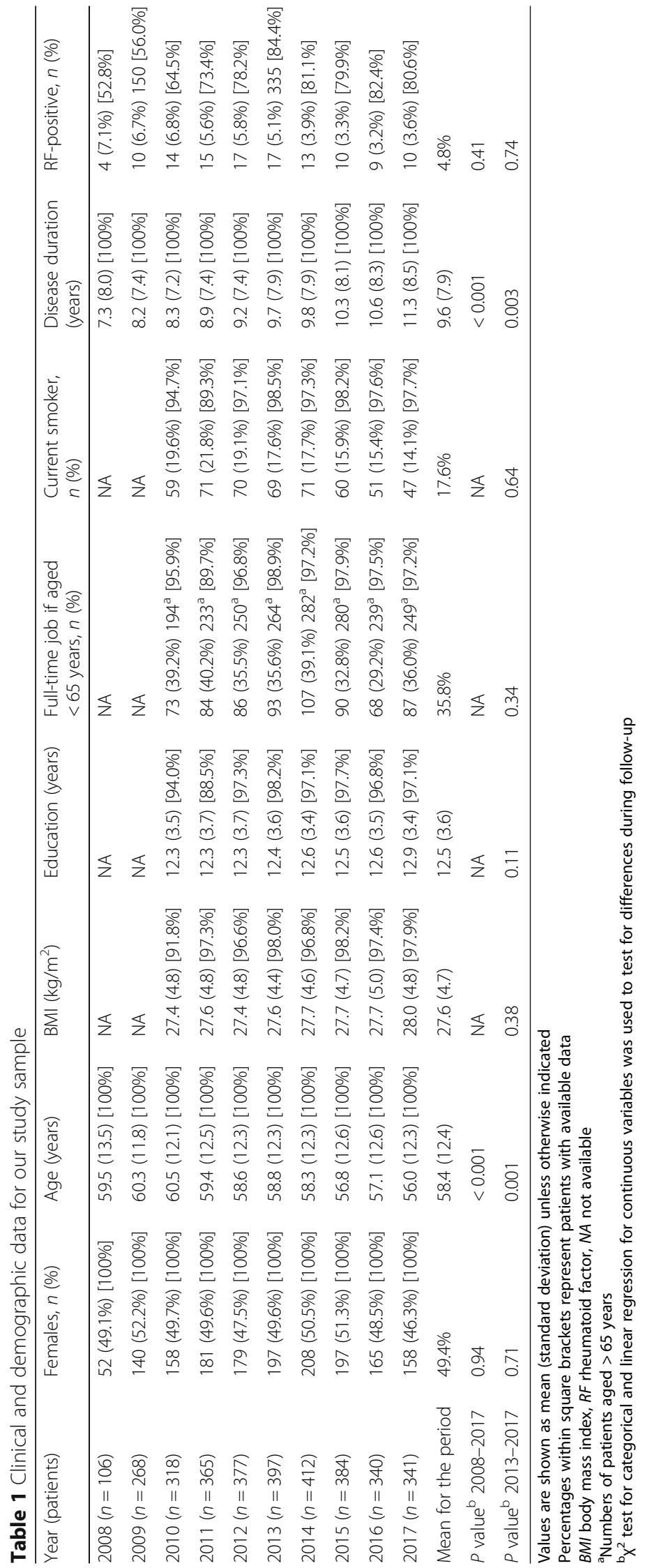




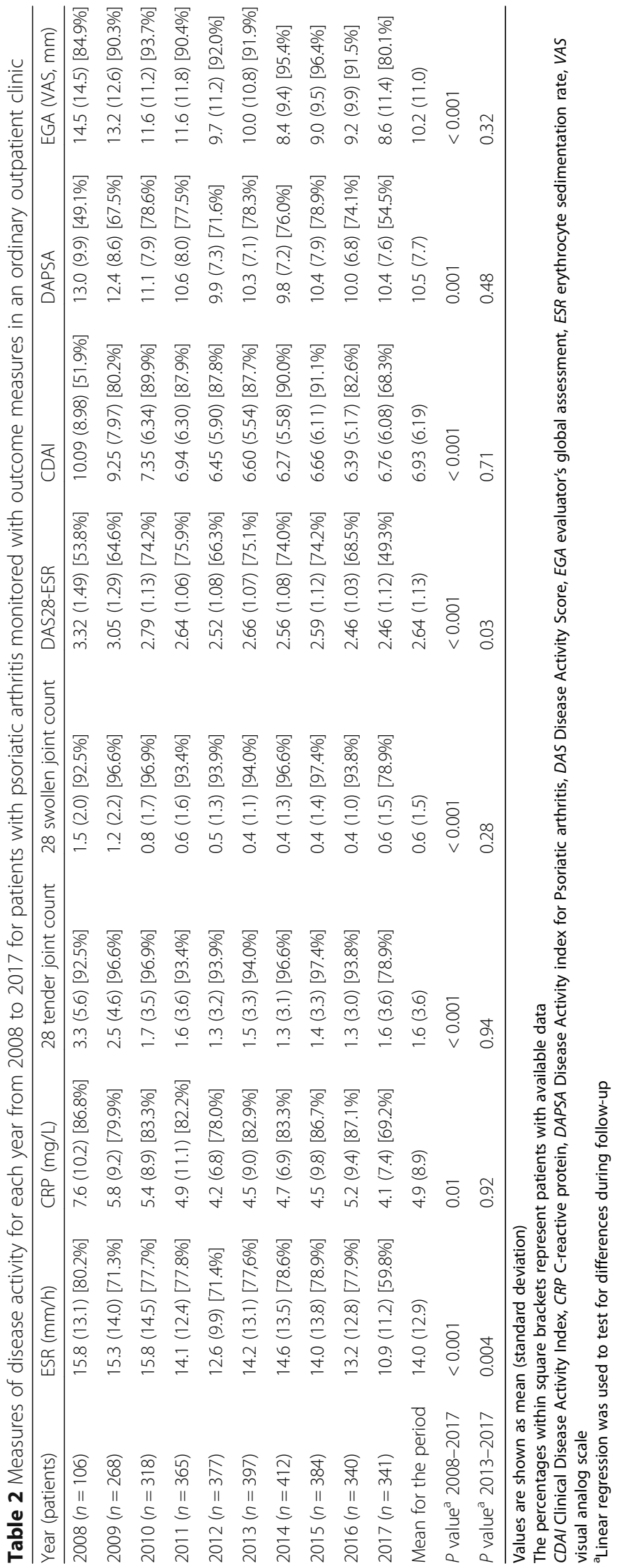




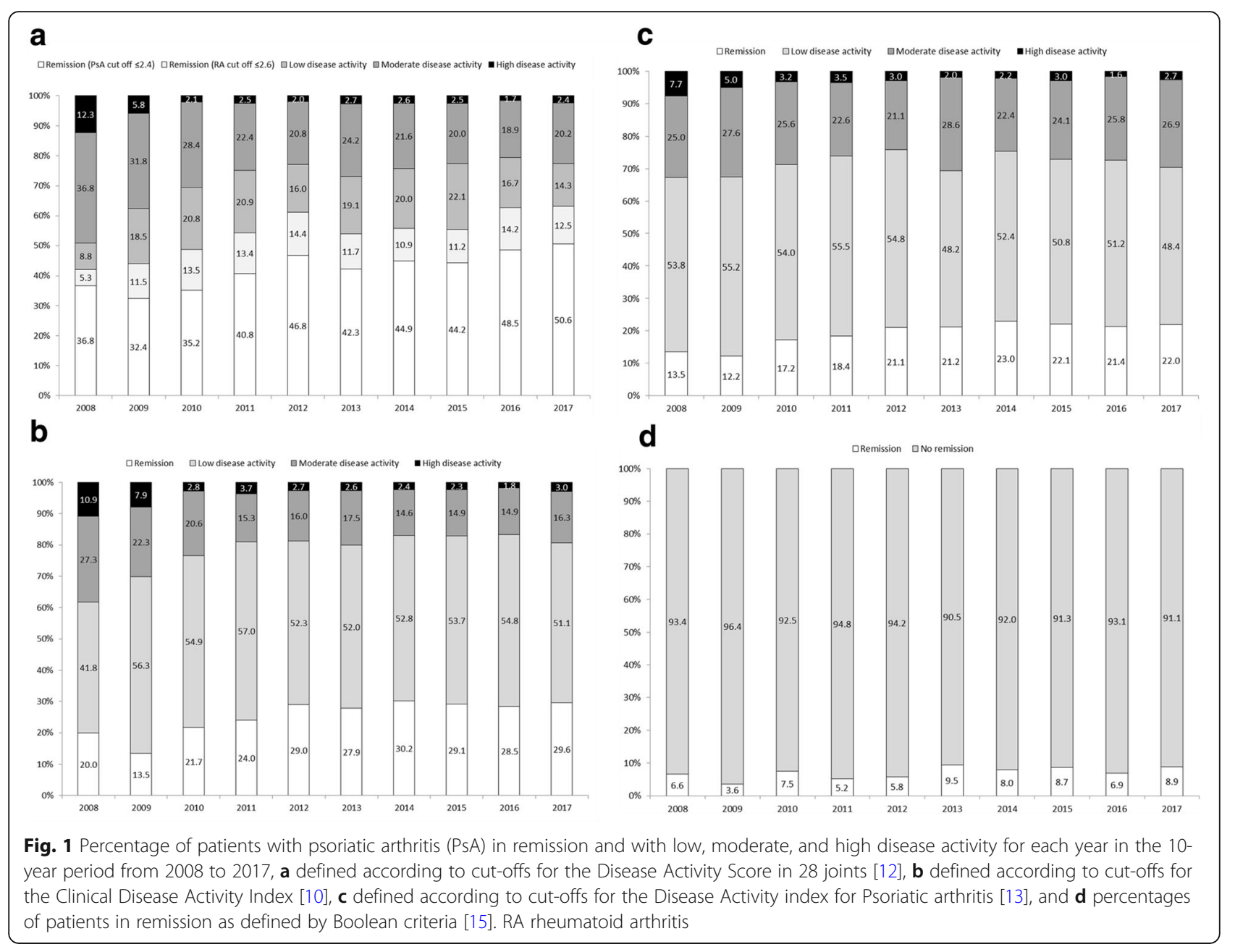

measures reflecting disease activity was observed. However, for the last 5 years of follow-up, a statistically significant improvement was only seen for ESR and DAS28-ESR and not for CRP, 28-joint count, CDAI, EGA, or DAPSA. Furthermore, no significant improvement in physical functioning or patient perception of, for example, fatigue, pain, and morning stiffness was found. A statistically significant increase in remission rates was only found for the entire period for DAS28-ESR (range $32.4 \%$ to 50.6\%) and CDAI (range $13.5 \%$ to $30.2 \%$ ), but not for ACR/EULAR Boolean (range $3.6 \%$ to $9.5 \%$ ) and DAPSA (range $12.2 \%$ to $23.0 \%$ ) remission or for DAS28-ESR (range 42.3 to $50.6 \%$ ) and CDAI (range 27.9 to $30.2 \%$ ) remission for the last 5 years of follow-up.

The remission rates observed in our PsA cohort seems to be lower than that found in our RA outpatient clinic population for the period 2004 to 2013, where remission rates increased significantly not only for DAS28-ESR but also for ACR/EULAR Boolean remission [7]. For comparison with the period 2008 to 2013, the remission rates in the reported RA patients increased from $24.7 \%$ to $55.5 \%$ for DAS28-ESR and from $6.8 \%$ to $17.7 \%$ for Boolean remission, whereas the remission rates in our PsA patients increased from $32.4 \%$ to $46.8 \%$ for DAS28-ESR and from $3.5 \%$ to $9.5 \%$ for the ACR/EULAR Boolean. However, this comparison should be interpreted with caution. Our data confirm the results from others that DAS28-ESR and CDAI (developed for use in RA) overestimates the remission rates in PsA compared with DAPSA [17], and this occurs even when using the recommended DAS28-ESR remission cut-off $\leq 2.4$ from Salaffi et al. to define remission in PsA [14]. When aiming for a less stringent T2T goal, including low disease activity, the differences between DAS28-ESR, CDAI, and DAPSA was less striking, as shown in Fig. 1.

The reduced access over the last years to modern treatment options with different modes of action other than TNF inhibitors in PsA compared with RA patients may partly explain the impression of a less significant improvement in clinical outcomes seen in our study. This is illustrated by $13.5 \%$ of RA patients from our outpatient clinic using non-TNF inhibitor bDMARDs in 2013, whereas the figures for our PsA patients were 1.3\% 


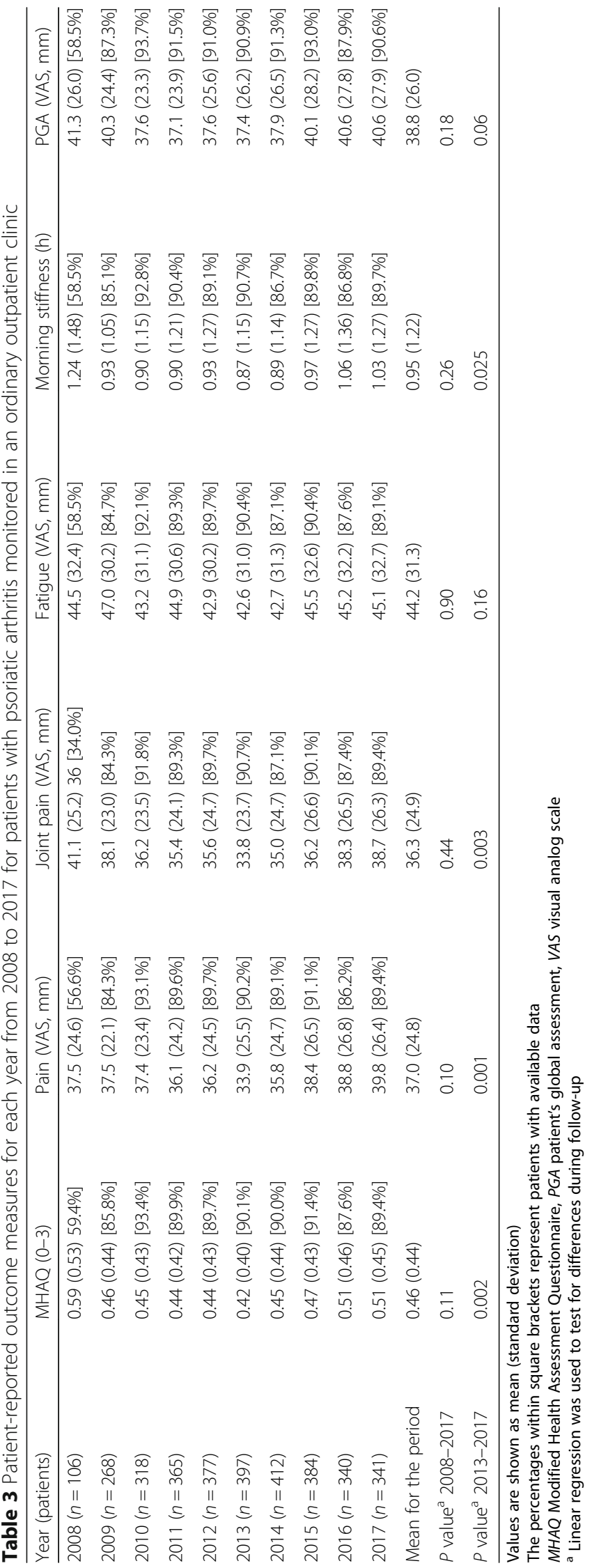




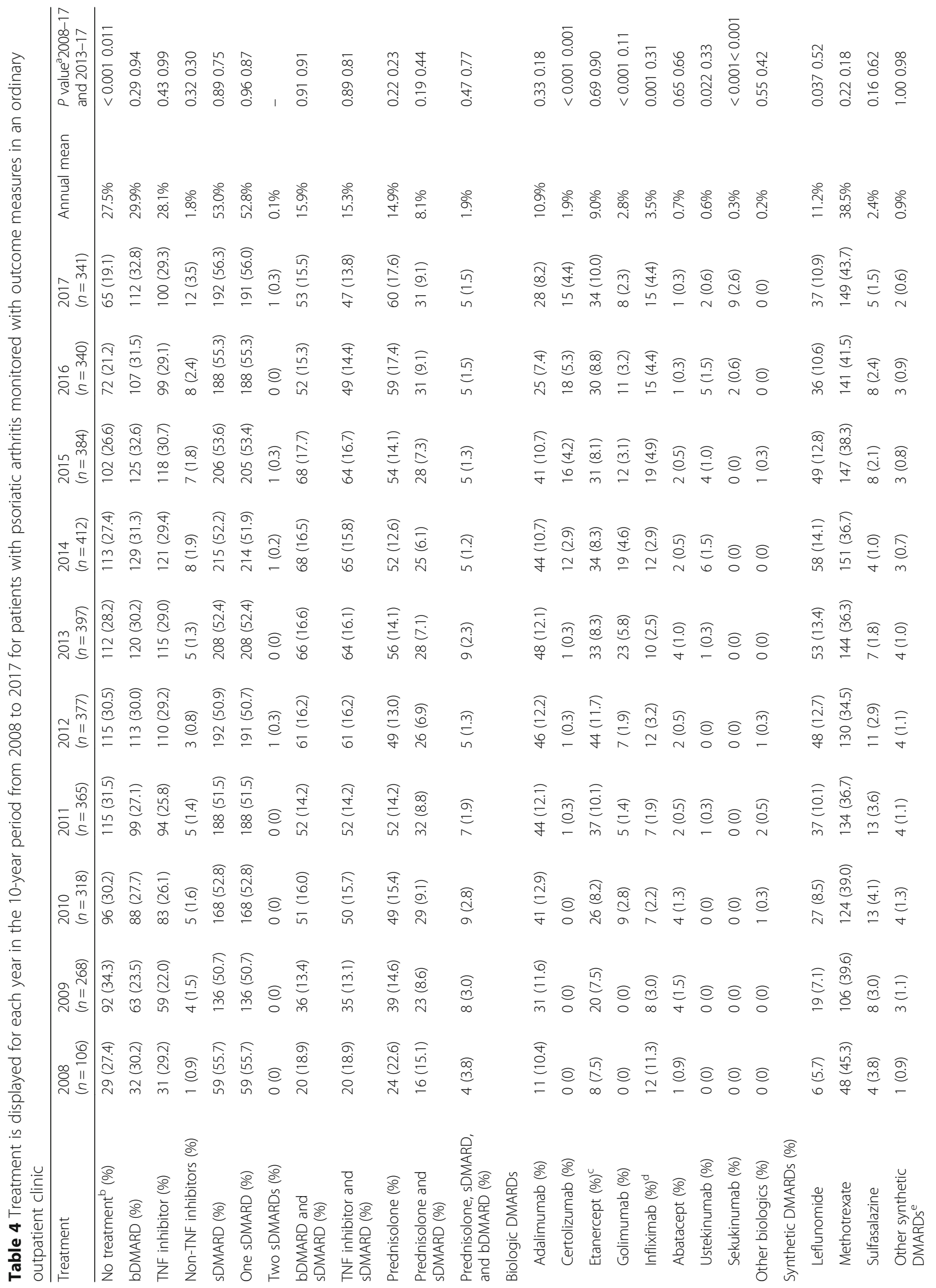




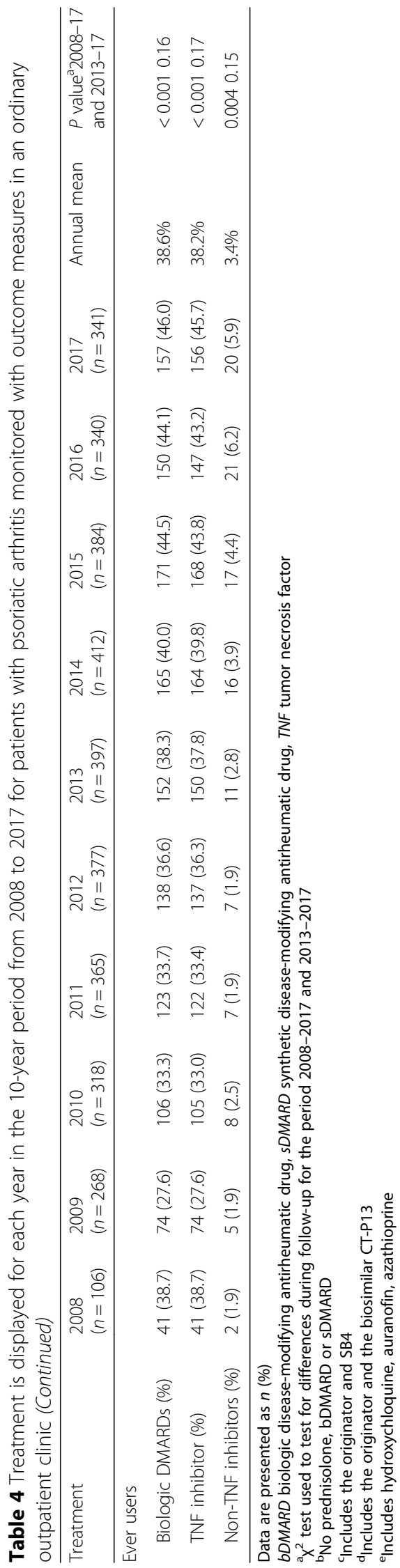


in 2013 and 3.5\% in 2017 [7]. The new drugs with mode of actions other than TNF inhibition used in our study included interleukin (IL)-12/23 inhibition (ustekinumab) and IL-17A inhibition (sekukinumab). The Janus kinase inhibitor tofacitinib has also been shown to be effective in treating PsA and is expected to soon reach the Norwegian market [18]. The number of PsA patients receiving no treatment (neither prednisolone nor DMARDs) in our study was in the range $20-30 \%$. These figures are high compared with those we reported in RA, where approximately $10 \%$ of RA patients received no prednisolone or DMARD treatment [7]. One reason for this may be that a large proportion of PsA patients present as mono- or oligoarthritis. For example, in a Norwegian PsA study, $5.8 \%$ had mono- and $22.9 \%$ had oligoarthritis [19]. These patients may be less likely than the polyarthritis PsA patients to be treated with DMARDs and this may partly explain the rather high proportion of PsA patients receiving no treatment in our study.

According to EULAR recommendations, it is recommended that RA patients in need of bDMARDs (especially TNF inhibitors) be treated in combination with sDMARDs because of the superior efficacy compared with monotherapy using either sDMARDs or bDMARDs [20]. In PsA there is no such strong evidence for combination treatment, as is also reflected in the EULAR recommendations for the management of PsA [21]. In our study, approximately $50 \%$ of the TNF inhibitor-treated PsA patients were also on sDMARDs. In comparison, approximately $75 \%$ of the TNF inhibitor-treated RA patients in 2013 were treated in combination with sDMARDs [7]. The rather high rate of bDMARD-treated PsA patients on concomitant sDMARDs may not only be explained by the physician's belief of a better effect using the combination, but could also be explained by a physician's concern about immunogenicity using bDMARD monotherapy without combination with, for example, methotrexate [22].

Challenges related to the heterogeneity of the PsA disease are reflected in the use of outcome measures in our study but are also shown by the different recommendations on use of outcome measures; some favor the use of unidimensional composite scores (e.g., DAPSA) focusing on articular inflammation [23], and some favor the use of multidimensional scores [24] including the different disease domains [5]. This heterogeneity of the PsA disease is therefore a major challenge when assessing the burden of disease both in the clinic and in research. Despite all these challenges, the concept of remission as a treatment goal in PsA is gaining more and more acceptance among rheumatologists. Higher scores for PROs (e.g., pain and fatigue) have been reported in PsA compared with RA, in spite of lower swollen joint counts [25]. The higher scores for pain reported in PsA patients seen in the literature may be explained by the inflammatory involvement of entheses and the presence of dactylitis which were not assessed in our study.

Despite recommendations for treating PsA patients to target, and agreement among rheumatologist favoring this approach, there is a discrepancy with what occurs in real life. This issue was explored in the study by Gvozdenovic and colleagues [26]. In their study, 83\% agreed that composite measures should be recorded regularly in RA patients; however, the real-life data revealed that in only $54 \%$ of the patients were composite scores actually recorded at $\geq 50 \%$ of the patient visits. There is reason to believe that this is also the case for PsA and, due to the heterogeneity of the PsA disease, the figures may be even worse in PsA than in RA. One strategy to improve the use of outcome measures in clinical practice could be the use of dedicated and trained nurse practitioners and physician assistants [27]. Further systematic education in outpatient clinics, for example implementing a learning collaborative, may also improve the adherence to a T2T strategy [28]. Another strategy could be developing patient self-assessment tools. For example, for the psoriasis area and severity index (PASI), a validated patient self-administered psoriasis score has been developed called the self-administered psoriasis area and severity index (SAPASI) [29, 30]. The implementation of outcome measures in daily clinical practice can also be facilitated by the use of computer technology as, for example, in our study and in DANBIO [31,32].

Our study has several limitations, including the use of outcome measures developed and validated for use in RA, no examination of the skin, nails, entheses or dactylitis, and the use of the 32-joint count and not the 66/68-swollen and tender joint count in the calculation of DAPSA [11]. This most likely has underestimated the DAPSA score in our PsA outpatients since the use of a reduced joint count has been shown to miss a significant number of PsA patients with active disease [33]. However, the mean difference between 28- and 32-joint count was minor in our study (mean 0.1 for swollen and 0.3 for tender joints). We also emphasize that the composite scores of DAS28 and CDAI with their cut-offs to define disease status and the Boolean remission criteria have not been validated for use in PsA. It is, however, a paradox that even recent approval of novel therapies for PsA have been based on clinical trials using primary endpoints derived from RA.

Other limitations of our study include assessment bias through examination by various physicians at various time points, and missing data, which may affect the internal validity of the results. The generalizability of the results may also have been affected by patient recruitment being only from one center. However, there is no 
obvious reason to believe that the examined PsA outpatient clinic cohort is different from other outpatient clinic cohorts in Norway. Despite all the limitations in this study, the long-term monitoring of PsA patients reflecting an entire PsA outpatient clinic population is in itself rather unique, and our data may thus be of interest both for clinicians and researchers in contributing to an increased understanding of the disease burden in PsA in our time.

\section{Conclusions}

The overall interpretation of our results is that there is still an unmet need in treating PsA patients to target, even in the era of biologic treatment. There is also an urgent need to develop, validate, and agree on feasible outcome measures to be used in ordinary clinical care, capturing the heterogenic expression of the PsA disease. However, in the meantime, our study should encourage clinicians to implement the use of available and feasible outcome measures in ordinary clinical care, for example DAPSA, to improve patient outcome.

\section{Abbreviations \\ ACR/EULAR: American College of Rheumatology/European League Against Rheumatism; bDMARD: Biologic disease-modifying antirheumatic drug; BMI: Body mass index; CDAl: Clinical Disease Activity Index; CRP: C-reactive protein; DAPSA: Disease Activity index for Psoriatic arthritis; DAS: Disease Activity Score; DMARD: Disease-modifying antirheumatic drug; EGA: Evaluator's global assessment; ESR: Erythrocyte sedimentation rate; MHAQ: Modified Health Assessment Questionnaire; MTP: Metatarsophalangeal; PGA: Patient global assessment; PRO: Patient-reported outcome; PsA: Psoriatic arthritis; RA: Rheumatoid arthritis; RF: Rheumatoid factor; SD: Standard deviation; SDMARD: Synthetic disease- modifying antirheumatic drug; T2T: Treat-to-target; TNF: Tumor necrosis factor; VAS: Visual analog scale}

\section{Acknowledgements}

We thank all secretaries, nurses, and doctors at the Division of Rheumatology, Department of Internal Medicine, Hospital of Southern Norway Trust who contributed to implementation of the strategy of monitoring PsA patients at the outpatient clinic

\section{Funding}

This study was supported by an unrestricted grant from Pfizer Norway.

\section{Availability of data and materials}

The datasets used and/or analyzed during the current study are available from the corresponding author on reasonable request.

\section{Authors' contributions \\ GH contributed to study conception and design, statistical analysis, and interpretation of results and was mainly responsible for drafting the manuscript. BM contributed to data collection, study conception, and interpretation of results. ST contributed to data collection, study conception, and interpretation of results. IJWH contributed to data collection, study conception, and interpretation of results. AD contributed to data collection, study conception, and interpretation of results. AK contributed to study design, interpreting statistical analysis, and interpretation of results. All authors were involved in drafting and revising the manuscript and approved the final version.}

\section{Ethics approval and consent to participate}

The approval for this study was given by the regional ethical committee (Regional etisk komite Midt-Norge 2010/3078). No consent from patients was needed according to the ethical committee, as all the data described above were collected as part of clinical care to facilitate treatment decisions.
Consent for publication

Not applicable.

\section{Competing interests}

GH is a founder and shareholder for DiaGraphIT AS, manufacturing the GoTreatI $T^{\oplus}$ Rheuma software. The remaining authors declare that they have no competing interests.

\section{Publisher's Note}

Springer Nature remains neutral with regard to jurisdictional claims in published maps and institutional affiliations.

\section{Author details}

'Division of Rheumatology, Department of Medicine, Hospital of Southern Norway Trust, Servicebox 416, 4604 Kristiansand, Norway. ${ }^{2}$ Department of Neuroscience, Division of Rheumatology, Norwegian University of Science and Technology, Trondheim, Norway. ${ }^{3}$ Department of Rheumatology, Martina Hansens Hospital, Bærum, Norway. ${ }^{4}$ Division of Rheumatology, Allergy, and Immunology, School of Medicine, University of California, San Diego, USA.

Received: 22 May 2018 Accepted: 4 July 2018

Published online: 02 August 2018

\section{References}

1. Smolen JS. Treat-to-target as an approach in inflammatory arthritis. Curr Opin Rheumatol. 2016;28:297-302.

2. Smolen JS, Aletaha D, Bijlsma JW, Breedveld FC, Boumpas D, Burmester G, et al. Treating rheumatoid arthritis to target: recommendations of an international task force. Ann Rheum Dis. 2010;69:631-7.

3. Smolen JS, Breedveld FC, Burmester GR, Bykerk V, Dougados M, Emery P, et al. Treating rheumatoid arthritis to target: 2014 update of the recommendations of an international task force. Ann Rheum Dis. 2016;75:3-15.

4. Smolen JS, Braun J, Dougados M, Emery P, Fitzgerald O, Helliwell P, et al. Treating spondyloarthritis, including ankylosing spondylitis and psoriatic arthritis, to target: recommendations of an international task force. Ann Rheum Dis. 2014:73:6-16.

5. Smolen JS, Schols M, Braun J, Dougados M, FitzGerald O, Gladman DD, et al. Treating axial spondyloarthritis and peripheral spondyloarthritis, especially psoriatic arthritis, to target: 2017 update of recommendations by an international task force. Ann Rheum Dis. 2018;77:3-17.

6. Ramiro S, Smolen JS, Landewe R, van der Heijde D, Dougados M, Emery P, et al. Pharmacological treatment of psoriatic arthritis: a systematic literature review for the 2015 update of the EULAR recommendations for the management of psoriatic arthritis. Ann Rheum Dis. 2016;75:490-8.

7. Haugeberg G, Hansen IJ, Soldal DM, Sokka T. Ten years of change in clinical disease status and treatment in rheumatoid arthritis: results based on standardized monitoring of patients in an ordinary outpatient clinic in southern Norway. Arthritis Res Ther. 2015;17:219.

8. Pincus T, Summey JA, Soraci SA Jr, Wallston KA, Hummon NP. Assessment of patient satisfaction in activities of daily living using a modified Stanford health assessment questionnaire. Arthritis Rheum. 1983;26:1346-53.

9. Prevoo ML, van 't Hof MA, Kuper HH, van Leeuwen MA, van de Putte LB, van Riel PL. Modified disease activity scores that include twenty-eight-joint counts. Development and validation in a prospective longitudinal study of patients with rheumatoid arthritis. Arthritis Rheum. 1995;38:44-8.

10. Aletaha D, Smolen JS. The simplified disease activity index (SDAI) and clinical disease activity index (CDAl) to monitor patients in standard clinical care. Best Pract Res Clin Rheumatol. 2007:21:663-75.

11. Schoels M, Aletaha D, Funovits J, Kavanaugh A, Baker D, Smolen JS Application of the DAREA/DAPSA score for assessment of disease activity in psoriatic arthritis. Ann Rheum Dis. 2010;69:1441-7.

12. van Gestel AM, Haagsma CJ, van Riel PL. Validation of rheumatoid arthritis improvement criteria that include simplified joint counts. Arthritis Rheum. 1998;41:1845-50.

13. Schoels MM, Aletaha D, Alasti F, Smolen JS. Disease activity in psoriatic arthritis (PsA): defining remission and treatment success using the DAPSA score. Ann Rheum Dis. 2016;75:811-8.

14. Salaffi F, Ciapetti A, Carotti M, Gasparini S, Gutierrez M. Disease activity in psoriatic arthritis: comparison of the discriminative capacity and construct validity of six composite indices in a real world. Biomed Res Int. 2014;2014:528105. 
15. Felson DT, Smolen JS, Wells G, Zhang B, van Tuyl LH, Funovits J, et al. American College of Rheumatology/European League Against Rheumatism provisional definition of remission in rheumatoid arthritis for clinical trials. Arthritis Rheum. 2011:63:573-86.

16. Taylor W, Gladman D, Helliwell P, Marchesoni A, Mease P, Mielants H. Classification criteria for psoriatic arthritis: development of new criteria from a large international study. Arthritis Rheum. 2006;54(8):2665-73.

17. Michelsen B, Diamantopoulos AP, Hoiberg HK, Soldal DM, Kavanaugh A, Haugeberg G. Need for improvement in current treatment of psoriatic arthritis: study of an outpatient clinic population. J Rheumatol. 2017;44:431-6.

18. Mease P, Hall S, FitzGerald O, van der Heijde D, Merola JF, Avila-Zapata F, et al. Tofacitinib or adalimumab versus placebo for psoriatic arthritis. $N$ Engl J Med. 2017;377:1537-50.

19. Madland TM, Apalset EM, Johannessen AE, Rossebo B, Brun JG. Prevalence, disease manifestations, and treatment of psoriatic arthritis in western Norway. J Rheumatol. 2005;32:1918-22.

20. Smolen JS, Landewe R, Bijlsma J, Burmester G, Chatzidionysiou K, Dougados $M$, et al. EULAR recommendations for the management of rheumatoid arthritis with synthetic and biological disease-modifying antirheumatic drugs: 2016 update. Ann Rheum Dis. 2017;76:960-77.

21. Gossec L, Smolen JS, Ramiro S, de Wit M, Cutolo M, Dougados M, et al. European League Against Rheumatism (EULAR) recommendations for the management of psoriatic arthritis with pharmacological therapies: 2015 update. Ann Rheum Dis. 2016;75:499-510.

22. Garces S, Demengeot J, Benito-Garcia E. The immunogenicity of anti-TNF therapy in immune-mediated inflammatory diseases: a systematic review of the literature with a meta-analysis. Ann Rheum Dis. 2013;72:1947-55.

23. Smolen JS, Schoels M, Aletaha D. Disease activity and response assessment in psoriatic arthritis using the disease activity index for psoriatic arthritis (DAPSA). A brief review. Clin Exp Rheumatol. 2015;33(5 Suppl 93):S48-50

24. Mease PJ, Coates LC. Considerations for the definition of remission criteria in psoriatic arthritis. Seminar Arthritis Rheum. 2018 Epub ahead; https://doi. org/10.1016/j.semarthrit.2017.10.021

25. Michelsen B, Fiane R, Diamantopoulos AP, Soldal DM, Hansen IJ, Sokka T, et al. A comparison of disease burden in rheumatoid arthritis, psoriatic arthritis and axial spondyloarthritis. PLoS One. 2015;10:e0123582.

26. Gvozdenovic E, Allaart CF, van der Heijde D, Ferraccioli G, Smolen JS, Huizinga TW, et al. When rheumatologists report that they agree with a guideline, does this mean that they practise the guideline in clinical practice? Results of the international recommendation implementation study (IRIS). RMD open. 2016;2:e000221.

27. Smith BJ, Bolster MB, Slusher B, Stamatos C, Scott JR, Benham H, et al. Core curriculum to facilitate the expansion of a rheumatology practice to include nurse practitioners and physician assistants. Arthritis Care Res. 2018;70:672-8.

28. Solomon DH, Losina E, Lu B, Zak A, Corrigan C, Lee SB, et al. Implementation of treat-to-target in rheumatoid arthritis through a learning collaborative: results of a randomized controlled trial. Arthritis Rheumatol. 2017:69:1374-80

29. Fleischer AB Jr, Rapp SR, Reboussin DM, Vanarthos JC, Feldman SR. Patient measurement of psoriasis disease severity with a structured instrument. J Invest Dermatol. 1994;102:967-9.

30. Feldman SR, Fleischer AB Jr, Reboussin DM, Rapp SR, Exum ML, Clark AR, et al. The self-administered psoriasis area and severity index is valid and reliable. J Invest Dermatol. 1996;106:183-6.

31. Hetland ML. DANBIO — powerful research database and electronic patient record. Rheumatology. 2011;50:69-77.

32. Sokka T, Haugeberg G, Pincus T. Assessment of quality of rheumatoid arthritis care requires joint count and/or patient questionnaire data not found in a usual medical record: examples from studies of premature mortality, changes in clinical status between 1985 and 2000, and a QUESTRA global perspective. Clin Exp Rheumatol. 2007:25(6 Suppl 47):86-97.

33. Coates LC, FitzGerald O, Gladman DD, McHugh N, Mease P, Strand V, et al, Reduced joint counts misclassify patients with oligoarticular psoriatic arthritis and miss significant numbers of patients with active disease. Arthritis Rheum. 2013;65:1504-9.

Ready to submit your research? Choose BMC and benefit from:

- fast, convenient online submission

- thorough peer review by experienced researchers in your field

- rapid publication on acceptance

- support for research data, including large and complex data types

- gold Open Access which fosters wider collaboration and increased citations

- maximum visibility for your research: over $100 \mathrm{M}$ website views per year

At BMC, research is always in progress.

Learn more biomedcentral.com/submissions 